\section{Inquéritos populacionais: aspectos metodológicos, operacionais e éticos}

\section{Population Surveys: methodological, operational and ethical aspects}

\section{Eliseu Alves Waldman'}

H. Maria Dutilh Novaes ${ }^{2}$

Maria de Fátima Militão de Albuquerque ${ }^{3}$

Maria do Rosário Dias de Oliveira Latorre ${ }^{4}$

Manoel Carlos Sampaio de Almeida Ribeiro ${ }^{5}$

Maurício Vasconcellos ${ }^{6}$

Ricardo Arraes de Alencar Ximenes ${ }^{7}$

Rita Barradas Barata ${ }^{8}$

Tânia Giacomo do Lago 9

Zilda Pereira da Silva ${ }^{10}$

1 Universidade de São Paulo, Faculdade de Saúde Pública

${ }^{2}$ Faculdade de Medicina da Universidade de São Paulo

${ }^{3}$ Universidade Federal de Pernambuco, Centro de Ciências da Saúde, Departamento de Medicina Clínica

${ }^{4}$ Universidade de São Paulo, Faculdade de Saúde Publica, Departamento de Epidemiologia

${ }^{5}$ Faculdade de Ciências Médicas da Santa Casa de São Paulo, Departamento de Medicina Social

${ }^{6}$ Instituto Brasileiro de Geografia e Estatística - IBGE

${ }^{7}$ Universidade Federal de Pernambuco, Centro de Ciências da Saúde, Departamento de Medicina Tropical

${ }^{8}$ Faculdade de Ciências Médicas da Santa Casa de São Paulo, Departamento de Medicina Social

${ }^{9}$ Faculdade de Ciências Médicas da Santa Casa de São Paulo, Departamento de Medicina Social

${ }^{10}$ Fundação Sistema Estadual de Análise de Dados - SEADE

Correspondência: Eliseu Alves Waldman, Universidade de São Paulo, Faculdade de Saúde Pública. Av. Dr. Arnaldo, 715 - Cerqueira Cesar - 01246-904, São Paulo - SP. E-mail: eawaldma@usp.br,
Os inquéritos populacionais vêm sendo usados em pesquisas epidemiológicas há praticamente um século, e nesse período amplamente aprimorados. Embora representem um dos desenhos mais tradicionais utilizados para a obtenção de informações populacionais sobre o processo saúde-doença, os inquéritos continuam a apresentar uma série de desafios.

A realização do seminário "Inquéritos populacionais: aspectos metodológicos, operacionais e éticos" pela Comissão de Epidemiologia da ABRASCO, Faculdade de Saúde Pública da USP e Departamento de Medicina Social da Faculdade de Ciências Médicas da Santa Casa, nos dias 17 a 19 de abril de 2007, possibilitou a discussão de diversos aspectos importantes relativos aos inquéritos.

Dado o caráter e a modalidade de organização do seminário foi possível, após cada apresentação, estabelecer momentos de discussão com o plenário, de forma que alguns pontos puderam ser destacados $\mathrm{e}$ registrados pelos relatores.

Este texto reúne os aspectos debatidos durante o seminário e tem a intenção de fornecer à Comissão de Epidemiologia da ABRASCO e aos pesquisadores interessados no tema, um panorama das questões que ainda necessitam de maior aprofundamento, constituindo assim subsídio para reflexões que podem contribuir para o aprimoramento dos inquéritos populacionais no país.

Os temas debatidos serão apresentados segundo os seguintes tópicos: aspectos éticos, aspectos metodológicos, questões operacionais, uso de inquéritos populacionais como estratégia na formação de pesquisadores, e questões gerais relacionados ao uso e aplicação dos inquéritos. Optou-se por apresentar em conjunto o teor das discussões, sem referi-las a cada sessão em particular, por considerar que esta forma seria a mais adequada para evitar sobreposições e dar maior organicidade ao conteúdo. 


\section{Aspectos éticos}

A partir da instituição das normas que orientam a conduta ética em pesquisas com seres humanos no país, na realização dos inquéritos populacionais os pesquisadores passaram a adotar o termo de consentimento como instrumento de aceitação da realização das entrevistas pelos entrevistados. Anteriormente, esta etapa consistia em obter apenas o consentimento verbal dos entrevistados, que em caso de não concordância poderiam sempre recusar sua participação.

A questão do termo de consentimento se desdobra em duas: a obtenção da assinatura em situações em que serão realizadas apenas entrevistas e o consentimento no caso de coleta de material biológico.

A exigência do termo de consentimento assinado pelo entrevistado, no primeiro caso, tem sido motivo de desgaste para muitos pesquisadores. Dada a baixa escolaridade da maioria da população e sua natural desconfiança em assinar qualquer tipo de documento, essa exigência tem significado, na prática, o aumento das perdas e recusas. Tendo em vista que, para as entrevistas realizadas no domicílio, os mecanismos de convencimento dos entrevistadores sobre os entrevistados são relativamente tênues, e que o risco oferecido pelo procedimento de coleta é praticamente nulo, a maior preocupação ética diz respeito a confidencialidade, aspecto plenamente garantido pelo código civil. Assim sendo, parece necessário revisar criteriosamente a exigência do termo de consentimento assinado, evitando o aumento desnecessário das recusas e perdas que podem resultar em vieses importantes nos dados obtidos. Nas entrevistas realizadas por telefone, por exemplo, o consentimento é oral, com a aprovação de Comitê de Ética.

Caso distinto é representado pela coleta de material biológico e a necessidade de armazenamento adequado. Embora no país a maioria dos inquéritos nacionais não utilize entre seus procedimentos habitu- ais a coleta de material biológico, com o aumento do interesse nas doenças crônicas e nos estudos de base genética, estes procedimentos deverão se tornar mais corriqueiros. Esse fato demandará a elaboração cuidadosa de termos de consentimento que possam prever os diferentes usos que poderão ser dados ao material coletado, evitando assim infringir os princípios éticos ao mesmo tempo em que se garante a realização das pesquisas necessárias a posteriori.

O desenvolvimento de procedimentos éticos específicos para pesquisas populacionais já em curso em outros países poderá auxiliar na revisão das recomendações brasileiras, devendo a Comissão de Epidemiologia da ABRASCO procurar se inteirar dos avanços obtidos e articular junto à CONEP (Comissão Nacional de Ética em Pesquisa) a elaboração de resoluções específicas para os inquéritos populacionais.

\section{Aspectos metodológicos}

Vários aspectos metodológicos foram objetos de debate durante o seminário. Destacam-se entre eles as questões relativas à amostragem, instrumentos de coleta de dados, formas de obtenção dos dados, influência dos respondentes, sazonalidade, conteúdos dos instrumentos, e nível de agregação das informações produzidas.

\section{Amostragem}

As questões referentes à amostragem podem ser agrupadas em aspectos relacionados com as técnicas amostrais e a representatividade da amostra.

Foram debatidas duas alternativas em relação aos procedimentos amostrais: o uso de uma amostra mestra, isto é, um único plano de referência amostral, feito pelo IBGE, para a realização dos diferentes inquéritos sob sua responsabilidade; e o uso de amostragem inversa como estratégia de minimização das perdas em con- 
textos urbanos, com variados problemas geradores de recusas e em face de orçamentos restritos.

O uso de uma amostra mestra poderá permitir, com um pequeno aumento no número de domicílios incluídos, obter amostras com maior representatividade no âmbito das unidades federadas, equilibrando os custos do desenho da amostra. A idéia central é que, a partir de uma amostra mestra, possa ser possível realizar o conjunto de inquéritos e eventualmente responder de modo mais rápido e oportuno a demandas específicas e conjunturais, visando fornecer dados para que os diferentes órgãos governamentais tomem decisões baseadas em informações. Os estudos nesse sentido estão apenas no começo por parte das equipes do IBGE.

Quanto à amostragem inversa, ela foi utilizada na Pesquisa Mundial de Saúde. No caso da PMS, além da estratificação em urbano/rural e porte populacional do município, os setores de cada estrato foram ordenados por renda média antes da sua seleção sistemática, o que implicou em uma estratificação implícita por renda. Somente nos setores selecionados foi aplicada a amostragem inversa. Para isto foram aleatoriamente selecionados 60 números de ordem de domicílio, a partir da listagem de domicílios feita pelo Censo Demográfico 2000, que eram visitados seqüencialmente e na ordem de seleção, até que 20 entrevistas fossem realizadas no setor.

Amostragem inversa pode ser definida como o processo de contar quantos domicílios precisam ser visitados para se obter o número prefixado de respostas (ou entrevistas realizadas). Ao longo do processo seqüencial de visita aos domicílios na busca das entrevistas, cada ocorrência (ou resultado da visita) era registrada. Dentre as ocorrências previstas estavam domicílio inexistente, unidade não-residencial, domicílio vago, domicílio sem adulto, recusa do domicílio, recusa do adulto selecionado, ausência temporária da família (viagem, férias) domicílio de uso ocasional.
Algumas dessas ocorrências foram incluídas porque a seleção dos domicílios foi feita a partir da listagem de domicílios do Censo Demográfico 2000, que poderia estar desatualizada no momento da coleta de dados da PMS. Além disso, todas essas ocorrências foram registradas na Folha de Coleta do Setor com dois objetivos: permitir a verificação pelo supervisor; e ter os elementos necessários para o cálculo dos pesos amostrais.

As estratégias habituais utilizadas na amostragem clássica, tais como selecionar uma amostra de reserva, substituir entrevistas não realizadas, usar over-sampling, apesar de muito freqüentes na prática, sobretudo porque nem sempre restam alternativas, são estratégias que causam viés nos estimadores. Mesmo a correção de não-resposta aplicada aos pesos amostrais e feita durante a expansão da amostra efetiva, apesar de muito comum, é também uma estratégia que incorpora viés à amostra. Os métodos que não causam viés são da classe da amostragem seqüencial, na qual se inclui a amostragem inversa.

Um método seqüencial, como a amostragem inversa, pressupõe um pouco mais de informação sobre o processo de coleta. Não basta saber se os domicílios foram ou não entrevistados. É necessário saber o que ocorreu em cada visita, para poder determinar se o domicílio pertencia à população alvo ou não, pois isto influi no cálculo do peso amostral. Por exemplo, no caso de um domicílio cujos moradores estão ausentes temporariamente, é necessário saber se existe algum morador que pertence à população alvo ou não. Para expandir a amostra inversa, a ponderação será feita com base na informação sobre quantos domicílios foram visitados; quantos domicílios pertenciam à população alvo da pesquisa, além de em quantos domicílios os indivíduos foram efetivamente entrevistados. Os detalhes do procedimento adotado estão apresentados em artigo sobre amostragem que consta do suplemento sobre a PMS, publicado pelos Cadernos de Saúde Pública (Vasconcellos MTL, Silva 
PLN, Szwarcwald CL. Sampling design for the World Health Survey in Brazil. Cad Saúde Pública, 2005, 21(Supl 1): S89-S99.).

A pesquisa sobre Economia Informal Urbana (ECINF), realizada pelo IBGE, é um exemplo de pesquisa onde a aplicação da amostragem inversa reduziria custos. Nessa pesquisa, o IBGE fez uma varredura completa (screening) dos domicílios de todos os setores sorteados, a fim de identificar aqueles onde residia pelo menos uma pessoa que trabalhasse no setor informal (tal como definido pela pesquisa). A amostragem inversa, neste caso, reduziria os custos, pois o screening também seria feito por amostragem. Ou seja, os domicílios selecionados seriam visitados e entrevistados se pertencessem à população alvo (ou seja, se houvesse pelo menos um morador no setor informal). Caso contrário, os resultados da entrevista de identificação seriam registrados e o domicílio seguinte seria visitado. Além de reduzir o custo por fazer o screening por amostragem, a amostragem inversa asseguraria o número desejado de entrevistas e o desenho não precisaria corrigir o tamanho da amostra por conta de uma taxa prevista de não-respostas.

Além das técnicas e procedimentos amostrais foram discutidos também alguns aspectos referentes à representatividade das amostras utilizadas em inquéritos. De modo geral, os inquéritos excluem parcelas mais ou menos importantes das populações, tais como os indivíduos institucionalizados, aqueles em "situação de rua" e outros segmentos geralmente formados por indivíduos que, por sua condição de vida, se distinguem da população em geral. Há pouco desenvolvimento de estratégias voltadas para a inclusão desses subgrupos populacionais.

O problema de representatividade ganha importância ainda maior nos inquéritos conduzidos por telefone, a exemplo do VIGITEL discutido durante o seminário. Surgiram questionamentos sobre a cobertura das linhas telefônicas, uma vez que a mesma varia nas diferentes capitais, sendo, em algumas delas, inferior a $50 \%$. Em- bora seja possível utilizar fatores de ponderação, ajustando as estimativas obtidas para representar a composição sociodemográfica da população estudada, isso só pode ser feito para os estratos que estiverem representados na amostra, ou seja, continuaria a desconsiderar aqueles sem telefone. Interroga-se até que ponto os excluídos (sem linha telefônica) diferem dos incluídos em aspectos relevantes para a investigação. Com a expansão da metodologia do inquérito telefônico para as 26 capitais existe o risco de se construir um sistema nacional cujas informações não sejam comparáveis, pois, em cada uma delas, pode-se estar trabalhando com estratos diferentes da população. A existência de mais de uma linha telefônica no domicilio poderia aumentar a chance de $o$ mesmo ser sorteado, introduzindo outro fator de desequilíbrio na amostra. Por outro lado, em áreas de menor poder aquisitivo existem muitos telefones móveis (celulares) e poucos telefones fixos.

Estas questões, para serem respondidas com base em evidências empíricas e não apenas em considerações teóricas, necessitam de outras pesquisas que comparem várias características sociodemográficas da população que possui ou não linhas de telefonia fixa e avalie as características de subgrupos populacionais como os moradores de favelas com ou sem acesso a telefones fixos ou celulares.

A experiência obtida pelos pesquisadores que participaram dessa primeira etapa de desenvolvimento do VIGITEL permite, entretanto, dizer que é possível o cálculo dos pesos para ajuste das estimativas dos diferentes estratos populacionais, pois, não existem estratos vazios em nenhuma das cidades, permitindo, portanto, o uso de fatores de ponderação para todos os estratos. Ressaltou-se que a lista de telefones utilizada para a construção da base amostral é mais ampla do que aquela de que se dispõe habitualmente, e as mudanças que ocorrem na lista de ano para ano são pequenas, não comprometendo a comparação entre anos sucessivos. 


\section{Instrumentos de Coleta}

Em relação aos questionários, utilizados como instrumentos de coleta preferencial nos inquéritos populacionais, foram apontadas na discussão questões de ordem formal e de conteúdo.

$\mathrm{Um}$ aspecto enfatizado tanto pelos apresentadores quanto pelos debatedores foi a importância de se utilizar questionários padronizados previamente validados, garantindo por um lado a aplicação de instrumentos já testados e com desempenho aprovado e, por outro, permitindo a realização de estudos comparativos, cada vez mais valorizados tanto no estudo de determinantes de saúde quanto na avaliação de programas e políticas de saúde.

Ainda em relação à elaboração dos questionários é importante ter em conta a necessidade de contar com instrumentos específicos para subgrupos populacionais, tais como crianças, idosos e migrantes, a fim de otimizar a obtenção de dados relevantes. Enfatizou-se a necessidade de adaptar diferentes questionários para grupos de imigrantes, levando em conta a língua e a adaptação cultural.

Chamou-se a atenção sobre a extensão dos questionários e o tempo de coleta de dados em grandes inquéritos populacionais, e sobre a necessidade de se ponderar a seleção das informações que deverão ser coletadas em função do tamanho dos questionários, tendo em vista a qualidade das informações. Nas entrevistas telefônicas, o tempo passa a ser um determinante crucial para a taxa de não respostas, embora este fato também seja relevante nas entrevistas pessoais.

Várias questões relativas a conteúdos dos questionários foram abordadas, porém destacamos aquelas que ainda necessitam maior investigação ou acúmulo de experiência no país: as medidas da auto-avaliação de saúde e morbidade referida, o uso de vinhetas como mecanismo de calibração da subjetividade do entrevistado, a operacionalização de classe social ou estratos socioeconômicos, as medidas indi- retas de consumo familiar (posse de bens duráveis) e os conteúdos relacionados com comportamentos discriminatórios com impacto sobre a saúde.

Houve um questionamento inicial sobre o critério para mensuração da autoavaliação do estado de saúde. Na literatura da área há basicamente duas propostas: a aferição em termos absolutos a partir da qualificação que o entrevistado faz de seu estado de saúde, sem usar nenhum parâmetro explícito de comparação; ou a classificação por referência a algum estado específico utilizado com parâmetro - por exemplo, comparando sua saúde com a de pessoas da mesma idade em sua comunidade. Ressaltou-se, ainda, a influência do nível socioeconômico, particularmente do nível de escolaridade, e a existência de um padrão de resposta que talvez superestime o estado de saúde avaliado como regular (categoria central na escala de Likert). A despeito das variações observadas, enfatizou-se a forte correlação entre as medidas de auto-avaliação e as medidas objetivas segundo dados da literatura, além da capacidade preditora da mortalidade em cinco anos demonstrada em diversos estudos.

O uso de vinhetas foi considerado potencialmente interessante no sentido de calibrar as respostas referidas sobre o estado de saúde e o uso de serviços, muito embora a experiência no seu uso em pesquisas epidemiológicas seja pequena e tenha funcionado de forma precária na Pesquisa Mundial de Saúde. Questionou-se ainda acerca da não adaptação das vinhetas à realidade brasileira e do tamanho das histórias utilizadas, que por vezes demandavam releituras. Esta é outra área que merece maior investimento em pesquisas. Tendo em vista que o uso de vinhetas baseia-se em técnicas projetivas que, ao colocar o indivíduo "em situação”, tornariam mais objetiva sua resposta, o desenvolvimento de vinhetas adequadas e com capacidade real de mobilizar e envolver o entrevistado é fundamental para o sucesso no uso da técnica. 
Particularmente em relação aos critérios de estratificação social permanecem problemas que foram se tornando cada vez mais importantes em função das características atuais da organização social. Como considerar a inserção no mercado informal de trabalho? Como diferenciar o trabalho doméstico em relação ao trabalho feminino em casa? Que bens deveriam ser considerados e se seria necessário ponderá-los, quando da utilização de uma estratificação segundo a posse de bens duráveis?

Foi assinalado que o crescimento do interesse em estudos de desigualdades sociais trouxe a revalorização do uso do conceito de classe social para os estudos de epidemiológicos, particularmente o conceito neomarxista de E. O. Wright, que tem sido usado em estudos europeus. Para todos esses questionamentos são necessários maior acúmulo de experiência e o desenvolvimento de investigações teóricas e metodológicas.

Em relação a temas importantes no contexto das desigualdades em saúde como o racismo, o sexismo e as discriminações de classe social, ressaltou-se o uso das questões padronizadas sobre discriminação percebida, a partir do referencial de Nancy Krieger e David Willians ainda pouco usados no país.

\section{Trabalho de campo}

Algumas das questões debatidas referem-se a problemas metodológicos decorrentes das condições de execução do trabalho de campo, ou seja, da etapa de obtenção dos dados. Foram abordados problemas relacionados com perdas seletivas, vantagens e desvantagens das entrevistas telefônicas, limitações dos tipos de respondentes, e sazonalidade.

Em relação às perdas diferenciais foram identificadas duas situações que podem acabar por produzir estimativas viesadas: a perda diferencial observada geralmente no estrato de renda mais elevada, motivada pela recusa e impossibili- dade de acesso dos entrevistadores aos entrevistados, e aquela observada nas áreas mais pobres, nos grandes centros urbanos, onde a violência urbana é o principal motivo das perdas. Em ambas as situações há necessidade do desenvolvimento de estratégias especificas para diminuir a ausência de resposta. Em relação às áreas violentas, sugeriu-se como alternativa a realização de inquéritos com entrevista por fluxo, por meio de entrevistas realizadas na rua, utilizando-se amostras por cotas.

Foram colocadas ainda algumas preocupações relacionadas à recusa em entrevistas telefônicas. Considerando o contexto em que se vive atualmente pode haver a proibição, em alguns domicílios, de fornecer informações por telefone. Questionouse se existe algum tipo de certificação que permita ao entrevistado identificar a origem da ligação. Interrogou-se se são coletadas algumas informações básicas dos indivíduos que se recusam a participar do estudo, para comparar as características dos que se recusaram com aqueles que participaram do estudo, e avaliar até que ponto houve viés de seleção.

Os pesquisadores que participaram da primeira etapa do VIGITEL informaram que alguns cuidados foram tomados para estimular a participação. Ao completar a ligação, o entrevistador informava que as perguntas não eram de ordem muito pessoal, que seria garantido o anonimato e que seria respeitado o direito de não participar. Um fator que possivelmente diminuiu a recusa foi a possibilidade de interromper a entrevista, se necessário, e continuá-la em outra ocasião, agendando de acordo com a disponibilidade do respondente. Defendeu-se que deve ser feita ampla divulgação do sistema para evitar problemas de recusa, como ocorre com o IBGE, que tem pequena proporção de não respostas.

A abordagem é uma etapa fundamental para conquistar a confiança da família e obter a entrevista. Quanto maior a população do município, mais difícil tem sido a realização das entrevistas. Nos municí- 
pios pequenos, as equipes da Pesquisa Mundial de Saúde, por exemplo, usavam carros do Ministério da Saúde e isto facilitou muito a abordagem e contribuiu para o aumento da taxa de resposta.

Ainda nos inquéritos telefônicos, com respeito à qualidade das informações obtidas indagou-se se, dependendo da informação solicitada, existem diferenças quando as mesmas são fornecidas por homens ou mulheres, ou por indivíduos com diferentes idades. Questionou-se até que ponto a interação do respondente com outras pessoas e o ambiente poderia alterar as respostas fornecidas. Outro ponto abordado foi que, como nesse tipo de entrevista não ocorre a observação direta do indivíduo, talvez haja mais propensão para viés de algumas informações específicas (por exemplo, peso, altura, etc.). Também pode haver a possibilidade de o respondente não ser a pessoa sorteada no domicílio.

Argumentou-se que a validade das informações obtidas no sistema VIGITEL foi testada utilizando-se como padrão ouro respostas provenientes de uma entrevista mais detalhada, porém também realizada por telefone. Não existem estudos de validação através de comparação com entrevista direta.

Ainda com relação ao respondente, foram discutidas as diferenças existentes nas respostas obtidas por um informante presente no domicílio, em substituição ao indivíduo efetivamente sorteado. Tendo em vista que a maioria dos dados obtidos nos inquéritos populacionais é do tipo autoreferido, pode haver diferença significativa nas respostas principalmente para questões relativas a comportamentos.

Em um inquérito nacional de saúde seria possível avaliar a concordância da auto-avaliação do estado de saúde de um indivíduo com a avaliação de outro membro da casa sobre o estado de saúde do mesmo indivíduo. Seriam possíveis ainda várias outras análises a partir de entrevistas com duas ou mais pessoas do mesmo domicílio. Por exemplo: Qual é a correlação entre classe social e auto-avaliação da saúde? Quem se auto-avalia como em bom estado de saúde também tem uma boa avaliação do outro?

Os estudos da coorte de Bambuí mostram que a distribuição da prevalência de problemas de saúde não muda se o respondente é a pessoa sorteada ou o proxy, ou informante. A predição da mortalidade apresentou o mesmo desempenho em uma situação ou outra. Além disso, se as prevalências entre as informações autoreferidas e as informações dadas pelo proxy (próximo) concordam e o objetivo é verificar a tendência pode-se considerar que as informações são satisfatórias.

Finalmente, outro ponto relativo às atividades de campo que pode ter repercussão nos dados coletados é a sazonalidade dos problemas de saúde. Qualquer estudo transversal padece dessa limitação, uma vez que realiza a coleta de informações em determinado período do ano. O uso de amostra mestra e coleta contínua poderiam minimizar esse problema.

\section{Aspectos operacionais}

Além das questões metodológicas apontadas, outras de caráter mais operacional também surgiram no debate.

Como questão mais geral, discutiu-se, a partir da experiência da Pesquisa Nacional de Demografia e Saúde, a conveniência de contratar institutos de pesquisa de opinião, com reconhecida capacidade, para a realização do trabalho de campo, garantindo assim a infra-estrutura adequada para a execução das atividades de campo.

\section{Base de referência amostral}

Os diferentes tipos de amostragem utilizados em inquéritos populacionais baseiam-se nas informações de setores censitários elaboradas pelo IBGE por ocasião do Censo Demográfico. A não-atualização da listagem de domicílios, principalmente em períodos afastados da realização do último censo, se reflete no aumento de domicílios vagos ou inexistentes (demolidos, 
transformados em não-residenciais etc.). O esquema de amostragem inversa contorna esses problemas reduzindo as perdas porque é possível substituir o domicílio sorteado. Na Pesquisa Mundial de Saúde, por exemplo, houve o caso de um setor de veraneio que foi selecionado e, como a maioria dos seus domicílios era de uso ocasional, o setor foi substituído. Ou seja, não há uma regra geral; cada caso deve ser alvo de análise para determinar a solução mais adequada.

O grande problema no uso da listagem do censo é que não se dá probabilidade de seleção aos domicílios criados após o referido censo. As demais ocorrências são normais e facilmente contornáveis em pesquisas domiciliares. Mesmo no caso de atualização da listagem pouco antes da coleta, como na PNAD, dá-se probabilidade de seleção ao domicílio vago (ele pode estar ocupado no momento da coleta) e ocorrem alterações após a listagem observadas apenas no momento da coleta (domicílio demolido, de uso não-residencial). Assim, o tempo de uso dos dados contidos na folha de coleta de um censo demográfico depende de muitas variáveis, que incluem orçamento, os objetivos da pesquisa, o grau de precisão buscado, o grau de desenvolvimento e crescimento da área pesquisada (em áreas mais consolidadas há pouca alteração, enquanto em áreas de crescimento acentuado a listagem fica logo desatualizada). Não dá, portanto, para estabelecer um prazo em anos de validade da listagem que funcione para todos os casos. Como regra geral, deve sempre ser considerada no orçamento a operação de listagem de domicílios.

Sorteados os domicílios, através de amostragem sistemática, por conglomerados ou por amostragem inversa, resta o problema do sorteio dos indivíduos. Alguns inquéritos optam pela inclusão de todos os indivíduos elegíveis, mantendo assim a estrutura de conglomerado na família; outros optam pelo sorteio de um dos indivíduos elegíveis utilizando tabelas com números pré-sorteados (tabelas de Kish).
Ao utilizar amostragem por conglomerados, o que acaba sendo inevitável em inquéritos populacionais, há perda de eficiência devida ao desenho: o efeito de conglomeração. Isto decorre do fato de os conglomerados usados serem dados pela forma de organização da população (setores, escolas e turmas, etc.) e serem muito homogêneos. Assim, acabam sendo entrevistadas em cada conglomerado muitas pessoas parecidas, ou seja, obtém-se informação semelhante em quantidade maior do que seria o desejável.

Existem algumas estratégias para criar conglomerados heterogêneos, evitando a perda de eficiência. Este procedimento requer o preparo da amostra, de tal modo que as unidades amostrais com maior diferença em relação a uma determinada variável são agrupadas gerando conglomerados mais heterogêneos.

\section{Protocolo de coleta}

Um protocolo de coleta que permita reproduzir os passos dos pesquisadores e supervisioná-los é essencial para garantir a qualidade na etapa de obtenção dos dados.

Os pesquisadores devem seguir o protocolo antes de considerar o domicílio como não-resposta e buscar outro domicílio para entrevistar. Neste protocolo se define o número de vezes em que é preciso retornar ao domicílio em horários distintos e diferentes dias da semana, como buscar informações com os vizinhos, e outros procedimentos como deixar uma carta no domicílio e fazer um mínimo de tentativas visando sempre manter o sorteio original e ter o mínimo de perdas.

No caso das amostras por conglomerados ou por amostragem inversa, em que os domicílios são visitados seqüencialmente, o protocolo de campo é importante para relacionar o número de domicílios visitados até que seja possível completar o número de entrevistas previamente estipulado. Nesses casos, valem também as regras de determinado número de tentati- 
vas, até que o domicílio seja considerado não elegível ou perda, dependendo do tipo de amostra utilizado.

No caso de o indivíduo sorteado não estar disponível para a entrevista, o domicílio deve ser considerado como não-resposta ou perda. Não se faz, de forma alguma, a seleção de outro adulto dentro do mesmo domicílio.

O uso de diferentes métodos ou técnicas para a obtenção de informação em uma mesma pesquisa é algo que precisa ser mais estudado para avaliar o impacto sobre os resultados. Combinar diferentes estratégias de entrevista (pessoal, por telefone, e-mail ou outros) pode ter efeitos sobre os dados.

\section{Realização de entrevistas telefônicas}

Foram levantadas algumas questões relacionadas à operacionalização das entrevistas telefônicas, sobretudo por suas implicações em termos da qualidade dos dados. Assim, indagou-se sobre a supervisão das equipes e sobre a linguagem usada nas entrevistas. Mesmo com o desenvolvimento de um sistema informatizado é necessário manter a supervisão das equipes de entrevistadores. A gravação das entrevistas possibilita a análise posterior e a indicação de nova entrevista quando necessário.

Quanto à linguagem, foram feitas adaptações para adequá-la a diferentes regiões do país em que o sistema foi implantado. Também foram levadas em consideração as diferenças de comportamento, de hábitos e horários, e de atividades no final de semana da população em diferentes cidades, visando atender às especificidades locais. Foram elaborados esclarecimentos específicos para cada região.

A possibilidade de expansão do sistema utilizado pelo VIGITEL para outras cidades além das capitais dependerá da consolidação dessa metodologia e do interesse do Ministério da Saúde na descentralização do sistema.

\section{Uso de inquéritos populacionais como estratégia na formação de pesquisadores}

Para estimular o debate sobre esse ponto apresentou-se a experiência de um mestrado em epidemiologia, cujo eixo de formação dos alunos é dado pela realização de um inquérito populacional abordando diferentes problemas de saúde de escolha dos alunos. No debate foram levantadas algumas questões que remetem à discussão sobre o equilíbrio entre formação teórica e formação técnica. Nesse sentido, apesar das vantagens em participar de todas as fases da pesquisa, questionaram-se as possíveis limitações na formação dos epidemiologistas ao experimentar um único tipo de desenho de estudo. Afirmou-se que não se deve privilegiar a experiência prática em detrimento de outras atividades. Também foi mencionado que a experiência apresentada é uma iniciativa interessante, que vai em direção contrária àquela adotada por outros programas de pós-graduação, que optaram por incrementar a participação dos alunos nas linhas/grupos de pesquisa dos docentes, o que, apesar de favorecer o aprofundamento teórico, pode restringir a participação a algumas etapas do trabalho, dependendo da fase de ingresso do aluno. Outro questionamento diz respeito a como operacionalizar a grande quantidade de temas em cada questionário e como lidar com o aprofundamento teórico de múltiplos assuntos de pesquisa.

A experiência relatada serviu também de ponto de partida para a discussão sobre o que se espera da nova conformação do mestrado, especialmente após as mudanças direcionadas para redução de prazo e incremento da produtividade. No debate, foi possível perceber as diferentes formas de conduzir os programas de pósgraduação e verificar que, para alguns, ainda permanece a preocupação de como dar conta adequadamente da formação teórica e metodológica em tão pouco tempo. Há uma preocupação em se discutir o que sig- 
nifica, no contexto atual da pós-graduação, o mestrado acadêmico que se encontra "prensado" entre o mestrado profissional e o doutorado. No debate ressaltou-se a importância de se compreender que a opção adotada ocorreu num contexto específico de um programa com poucos alunos e docentes e que, embora haja consciência das limitações, esse modelo era o que poderia oferecer melhores resultados na avaliação dos docentes. Entende-se o mestrado como uma etapa, o passo inicial da formação. Assim, a avaliação é de que a decisão na ênfase para o aluno ter experiência completa de pesquisa foi acertada, tendo sido vista como proveitosa na sua formação. Rebateu-se a idéia de restrição metodológica, uma vez que os alunos do mestrado têm momentos de interação com outros alunos e docentes, não ficando restritos, do ponto de vista teórico, apenas aos aspectos do inquérito. Quanto ao aprofundamento teórico, a maioria dos temas concentra-se na área de competência dos orientadores e, em casos específicos, recorre-se à co-orientação para os assuntos de menor domínio, sendo que, para o mestrado, não se exige um conhecimento tão aprofundado.

Destacou-se que os inquéritos possuem lugar importantíssimo na formação em pesquisa, e não apenas em relação às técnicas; os inquéritos têm propiciado experiência enorme de aprendizado, inclusive para os próprios pesquisadores, possibilitando unir ensino e pesquisa.

Por fim, merece destaque o fato de a maioria das intervenções ter demonstrado uma demanda latente para ampliação do debate sobre as estratégias de formação na área de epidemiologia. Isto se consubstanciou em sugestão de que a Revista Brasileira de Epidemiologia aborde o tema - no formato de dossiê ou suplemento -, visando aproveitar o acúmulo que se tem sobre o assunto, estimulando a reflexão sobre as políticas de formação, expondo os programas de pós-graduação que estão dando certo ou não, e examinando problemas e soluções experimentados pelos mesmos.

\section{Importância dos inquéritos nacionais e outros aspectos gerais}

Com relação ao uso dos inquéritos populacionais, além de sua aplicação em atividades de formação de novos pesquisadores foram apontadas as potencialidades para o estudo e o monitoramento das desigualdades sociais em saúde e para o conhecimento do panorama nacional em saúde, seja na avaliação dos problemas de saúde seja no estudo das formas de acesso e utilização dos serviços de saúde.

A realização de inquéritos nacionais periódicos e regulares foi considerada necessária para que se possa conhecer a realidade epidemiológica da população a partir de cortes transversais periódicos, seqüenciados. Eles abrangem um amplo espectro de problemas de saúde, permitindo correlacionar os resultados com as condições de vida das populações, conhecer a distribuição dos fatores de risco e a percepção das pessoas a respeito do seu estado de saúde. Podem ainda dar voz aos usuários dos serviços de saúde, possibilitando assim conhecer o seu grau de satisfação. Permitem ainda avaliar as políticas públicas implementadas, analisar temporalmente o acesso às políticas promotoras de saúde, comparar padrões de saúde entre áreas geográficas e calcular os custos das doenças para o sistema de saúde.

A discussão do modelo adotado nas pesquisas mundiais de demografia e saúde (DHS) permitiu analisar as vantagens de se manter um corpo central da pesquisa para a comparabilidade internacional (horizontal) e as análises de tendência (longitudinal), e a opção de agregar módulos temáticos considerados oportunos em cada país.

A apresentação da Pesquisa Nacional de Demografia e Saúde motivou ainda a discussão de um aspecto central em inquéritos: as tensões ideológicas que disputam os marcos teóricos sobre assuntos como a fecundidade com reflexos diretos sobre as fontes e os volumes de financiamento desses estudos. As implicações políticas ime- 
diatas das informações produzidas em determinados tipos de inquéritos colocam, para os pesquisadores, de maneira muito objetiva, questões éticas e políticas que demandam posicionamento claro e compromisso com a melhoria da qualidade de vida das pessoas.

No debate sobre a adoção de inquéritos nacionais periódicos e regulares surgiu a preocupação em preservar inquéritos já existentes, como a PNAD, cujas informações são baseadas em entrevistas e cobrem questões importantes como o acesso aos serviços de saúde e exames de rastreamento. A PNAD tem tamanho de amostra que permite fazer análise estratificada para várias situações e grupos populacionais. Entretanto, o suplemento de saúde é limitado pela necessidade de se manter o questionário dentro de certa extensão, uma vez que se acopla a uma pesquisa mais detalhada das condições socioeconômicas da população.

Um dos aspectos enfatizados na discussão foi a necessidade de otimizar a relação entre custos e benefícios advindos da realização de inquéritos populacionais. Normalmente, os inquéritos geram grande quantidade de dados, muitas vezes maior que a capacidade de análise e utilização dos mesmos. Para potencializar o uso dos dados e reduzir proporcionalmente os custos é importante que os bancos gerados sejam públicos e possam ser analisados por vários grupos de pesquisadores, de diferentes perspectivas, fornecendo inúmeras análises para utilização pelos gestores do sistema de saúde, a exemplo do que vem ocorrendo com os dados dos suplementos de saúde da PNAD.

Outra questão destacada foi a possibilidade de nos inquéritos, diferentemente do que ocorre nos sistemas regulares de informações em saúde, focalizar aspectos relacionados com a promoção da saúde, o estado de saúde e condutas preventivas, ao invés de se limitar aos problemas, agravos e doenças.

Uma preocupação que surge face à proposta da realização de inquéritos nacionais de saúde periódicos e regulares refere-se ao nível de agregação das informações produzidas. Informações referentes ao nível nacional servirão para subsidiar a formulação de políticas do governo federal, mas a maioria delas não serviria para subsidiar ações nos Estados e municípios. Tendo em vista o caráter fortemente descentralizado do sistema nacional de saúde, as informações válidas para o âmbito nacional não poderão ser tomadas como indicativas da situação regional ou local.

Concorda-se que os INS não terão poder para realizar inferências locais, porém poderão criar um padrão nacional que servirá de base aos outros níveis de organização do sistema. A padronização de perguntas para o inquérito favorece o seu uso em níveis diferentes, permitindo pensar em uma hierarquia de inquéritos de diferentes abrangências. $\mathrm{O}$ estado e o município podem trabalhar uma amostra utilizando a mesma metodologia para realizar o inquérito. Outra possibilidade é a vinculação dos dados primários com os secundários.

O uso dos inquéritos como ferramentas para o estudo e monitoramento das desigualdades sociais em saúde também foi debatido, ressaltando-se o fato de que existe clara evidência, por exemplo, da influência da distribuição de renda sobre a saúde e dos mecanismos que levam à desigualdade; entretanto, é preciso identificar como o sistema de saúde pode agir para diminuir essas desigualdades. Por exemplo, o que o PSF está fazendo para diminuir as desigualdades? O Programa Bolsa Família que, segundo os economistas, produziu impacto na economia, também teve impacto sobre a saúde? Essa pequena ajuda faz a diferença? Qual o impacto da distribuição dessa renda sobre a saúde? O que o Estado brasileiro tem feito para diminuir as iniqüidades através das políticas sociais?

A utilização do conhecimento sobre os determinantes das desigualdades para formular ações políticas nem sempre é possível porque esse uso não depende exclusivamente da dimensão técnica e sim da 
dimensão política. Alguns determinantes não são manipuláveis no campo da saúde, mas é preciso divulgar esse conhecimento para a sociedade.

Uma questão que apareceu algumas vezes na discussão plenária foi o da aplicabilidade dos resultados dos inquéritos. Quais as experiências recentes de incorporação de resultados de inquéritos como, por exemplo, da pesquisa mundial de saúde, pela SVS/MS? A utilização dos inquéritos de saúde para o planejamento de intervenções é bem recente. Há apenas algumas experiências pontuais. Com relação a esse ponto foi comentado que dois dos principais exemplos de inquéritos de saúde por entrevistas em domicílios tiveram sucesso pela forte influência dos gestores públicos, que os realizaram com propósitos muito precisos. Num dos casos, o Health Household Interview Survey dos EUA, atendia explicitamente a uma necessidade de se obter consolidados nacionais de informações que se encontravam dispersas no sistema de saúde do país. Em outro, o Canadian Health Survey, a proposta tinha o aval do honorável Marc Lalonde, então Ministro da Saúde, que havia introduzido o conceito de Health Field e buscava legitimar suas idéias através de dois elementos essenciais do Life Style, a saber, Physical Fitness e Mental Fitness, ambas as aptidões exploradas em questionários auto-aplicáveis.

Ou seja, existem ainda muitos aspectos a serem considerados no desenvolvimento teórico e metodológico dos inquéritos populacionais, e parte considerável das respostas às indagações formuladas pelos participantes do seminário só encontrarão resposta na medida em que a experiência e a reflexão sobre a realização de inquéritos populacionais forem sendo acumuladas e compartilhadas pela comunidade científica e pelos organismos encarregados de sua realização. 